\title{
Treatment of Early Breast Cancer
}

\author{
Michael Untch \\ Frauenklinik, HELIOS Klinikum Berlin-Buch, Germany
}

In the treatment of early breast cancer patients we have seen tremendous advances especially in recognizing molecular properties leading to individualized therapy, including targeted therapies. At the same time, improvements in curing our breast cancer patients are also linked to quality controlled screening programs.

Prof. Heywang-Köbrunner from Munich, one of the leading German radiologists with expertise in breast cancer detection and minimal invasive diagnostic procedures and her colleagues have put together a very balanced article on mammography screening [1], obviously focusing on advantages, but also taking into account possible disadvantages and some aspects of overdiagnosis. Today, there is no doubt that mortality can be significantly reduced by national screening programs. The use of modern mammographic techniques along with quality assurance is shown using the example of the screening program in Germany.

The advances of breast cancer surgery can be demonstrated by the reduction of morbidity of the axillary surgery. Prof. Thorsten Kühn, one of the worldwide leading specialists in sentinel lymph node biopsy procedure, is giving us a state of the art reflection on axillary surgery and also focuses on the recent advances in additional reduction of axillary surgery in patients with a minimal involvement of sentinel lymph nodes (micrometastases, macrometastases) [2]. There is also a high need to include the sentinel lymph node procedure in patients with primary systemic therapy. This topic is also addressed in his article and a comprehensive practical view is given.
The reduction in surgery has been accompanied by individualized therapeutic approaches in accordance with prognostic and predictive markers in our breast cancer patients. This topic is discussed by Prof. Elmar Stickeler from Freiburg i.Br. [3]. In his article he shows which of the modern biological molecules have made their way from the laboratory to clinical routine allowing us to avoid overtreatment and giving us the opportunity to use more effective individualized therapies, including targeted therapies.

Last but not least, Prof. Florian Schütz from Heidelberg gives an overview on the modern adjuvant systemic therapies of our breast cancer patients, an area which has seen a significant improvement over the last years and decades [4]. His article summarizes advances in chemotherapy, endocrine therapies and targeted therapies. The role of anthracyclines and taxanes and also the role of dose-dense and dose-escalated chemotherapy are analyzed from both sides: efficacy versus side effects and need for supportive therapies. The role of neoadjuvant or primary chemotherapy is also summarized and modern approaches are described. The optimal endocrine treatment strategies after more than 10 years of experience with aromatase inhibitors are also summarized. The question of length of treatment, sequence and side effects are given in his article.

In summary, this journal issue on early breast cancer gives us practical advice on screening, lowering the morbidity of surgery, and recognizing molecular targets, therefore allowing us more individualized therapies in breast cancer.

\section{References}

1 Heywang-Köbrunner SH, Hacker A, Sedlacek S: Advantages and disadvantages of mammography screening. Breast Care 2011;6: DOI: $\underline{10.1159 / 000329005 .}$.
2 Kühn T: Sentinel lymph node biopsy in early breast cancer. Breast Care 2011;6: DOI: 10.1159/ 000329193.

3 Stickeler E: Prognostic and predictive markers for treatment decisions in early breast cancer. Breast Care 2011;6: DOI: 10.1159/000329471.
4 Schuetz F: Adjuvant systemic therapy of breast cancer. Breast Care 2011;6: DOI: 10.1159/ $\underline{000329336}$

\section{KARGER}

Fax +497614520714

Information@Karger.de

www.karger.com (c) 2011 S. Karger GmbH, Freiburg

1661-3791/11/0063-0177\$38.00/0

Accessible online at:

www.karger.com/brc
Prof. Dr. med. Michael Untch

HELIOS Klinikum Berlin-Buch

Frauenklinik, Interdisziplinäres Brustzentrum

Schwanebecker Chaussee 50,13125 Berlin, Germany

Tel. +49 30 9401-53300, Fax -53309

michael.untch@helios-kliniken.d 